\title{
\% Función significante, función simbolizante y dinamismo simbólico. Estudio desde algunas aportaciones de la filosofía de Xavier Zubiri
}

\section{José Raúl Cervera Milán Universidad Iberoamericana Ciudad de México}

Al profesor Luis Maldonado Arenas y al compañero Ricardo Falla.

La aparente pobreza conceptual de las culturas primitivas implica, no una incapacidad de hacer teoría, sino su pertenencia a un estilo de pensar netamente diferente del "estilo» moderno fundado sobre los esfuerzos de la especulación helénica. M. Eliade

Resumen: Este escrito pretende ofrecer algunos elementos a través de los cuales se posibilite contextualizar y enfocar mejor la pregunta sobre la naturaleza de las acciones y las cosas significantes y simbólicas. El trabajo se desarrolla en torno a tres nociones básicas: la función significante, la función simbolizante y los dinamismos simbólicos. El camino que se propone para lograr este cometido se aventura por los intersticios de la interdisciplinariedad; en este caso, a través del diálogo entre algunos de los mejores logros de varias disciplinas que tienen que ver con el lenguaje y con el manejo de los símbolos. Por otro lado, los análisis aportados por la noología de Xavier Zubiri, así como unos cuantos elementos de su filosofía acerca de Dios y del ser humano. Los hallazgos de las disciplinas experimentales permiten describir el funcionamiento de la función significante y 
la función simbolizante. En el punto de llegada-siempre provisional-constatamos que lo que explica noológicamente la naturaleza de los dinamismos simbólicos y los distingue convenientemente de la función simbolizante es la aportación zubiriana acerca de la marcha de la razón.

Palabras clave: función significante, función simbolizante, dinamismo evocante o simbólico.

Abstract: The present work intends to offer some elements in which it will be possible to enable, focus and bring in context the question on the nature of actions and symbolic elements. The study will be developed around three notions: the signifier function, the symbolizing function and the symbolizing dynamisms. The path that is proposed to achieve this goal, one hand, goes through interdisciplinary interstices, in this case, through dialogue among some of the best accomplishments of various disciplines which are related to the language and the symbols management, and on the other hand on the analysis provided by the Noology of X. Zubiri, as well as some of his philosophical elements associated to God and the Mankind. The findings of experimental disciplines allow to describe the operation of the signifier function and the symbolizing function. In the end -always provisional-we confirm that, the nature of the symbolic dynamisms explains noologically and distinguishes conveniently the symbolling function, is the zubirian contribution about reasoning March.

Key words: signifier function, symbolizing function, evoking or symbolizing dynamism.

\section{Introducción}

La presente reflexión acerca de la naturaleza y el funcionamiento de los signos y los símbolos pretende dar continuidad a la tesis de posgrado defendida por el autor de este escrito en la Universidad Pontificia de Salamanca, en 1999, para obtener el título en Teología popular y teología profesional en
América Latina. Un acercamiento al concepto de método teológico de Juan Carlos Scannone. En tal escrito llegábamos a la conclusión de que el modo de acceder y de maniobrar con la realidad, en el caso de quienes expresan sus experiencias religiosas a través de los moldes culturales propios de los descendientes 
de los pueblos originarios de América y de otros sectores marginales, es eminentemente -aunque no exclusivamentesimbólico. La pregunta que surgió a continuación fue: ¿Y qué es lo simbólico? En el transcurso de este trabajo veremos que la respuesta que se ofrece a esta pregunta se encuentra relacionada con la manera cómo se entiendan los signos.

El material presentado en este artículo forma parte de un escrito más amplio que está siendo preparado para ver la luz. El tema y el propósito de ambos textos son los mismos, la diferencia estriba, fundamentalmente, en que el presente trabajo constituye una reducción cuantitativa de aquél. El material común a ambos pertenece, sobre todo, al ámbito de la filosofía. En términos mayoritarios, la reducción se debe a la supresión de las aportaciones provenientes de los campos lingüístico, semiológico y de la filosofía hermenéutica. $A$ este respecto sólo se encontrarán algunas indicaciones breves, indispensables para la comprensión del conjunto.

El trabajo-fuente ha sido elaborado desde una pretensión de interdisciplinariedad, muy riesgosa por lo demás. El ritmo de la investigación se ha ido desarrollando a través de un ir y venir constantes desde las aportaciones de la lingüística y la semiología hacia las propuestas de la filosofía, y viceversa. Su núcleo metodológico consiste, precisamente, en el esfuerzo por articular algunas aportaciones de ambas vertientes del pensamiento contemporáneo en torno a los temas que aquí se tratan. En cuanto a las fuentes, en el caso de la lingüística nos hemos apoyado en algunos de los autores clásicos, los padres de esas disciplinas, y en varios de sus teóricos contemporáneos. En contraste, en el campo filosófico hemos incorporado predominantemente los puntos de vista de Xavier Zubiri Apalategui, especialmente el Curso de noología, pero también algunos elementos de la filosofía de Dios y la antropología.

El estudio se desarrollará en dos partes: en la primera se esclarecerán las nociones de función significante y función simbolizante, desde una perspectiva lingüística, simbológica y noológica. En la segunda se analizará la naturaleza de los dinamismos simbólicos, desde un enfoque, primero simbológico y, a continuación, noológico. 


\section{Las funciones significante y simbolizante}

En esta primera parte pretendemos esclarecer en qué consiste la naturaleza de las funciones significante y simbolizante. Lo haremos en dos pasos, en primer lugar, presentaremos una conceptualización de dichas funciones desde la racionalidad propia de la lingüística y la simbología. Posteriormente, nos detendremos en el esclarecimiento de su naturaleza desde una perspectiva noológica.

\section{Estatuto lingüístico y simbológico}

\section{Preliminares}

Normalmente, las palabras, los signos y los símbolos se definen por el fenómeno de la significación y el de la comunicación, si bien la naturaleza de sus componentes elementales y otras consideraciones han llevado a distinguir entre el enfoque lingüístico y el semiológico -no sin tensiones entre ambos- El primero se ocupa, tradicionalmente, del lenguaje; el segundo suele abarcar el estudio de los signos no lingüísticos y los símbolos. Para nuestras propuestas hemos tenido especialmente en cuenta las aportaciones clásicas de Ferdinand de Saussure (1982) y de Louis Hjelmslev (1971). Paralelamente se ha desarrollado la filosofía del lenguaje y la hermenéutica. En relación con esta segunda disciplina, ha sido relevante para nuestra reflexión el aporte de Paul Ricoeur (1990).
Ahora bien,la distinción básica que queremos introducir en este campo es de carácter tripartito. Por un lado se encuentra lo que las disciplinas correspondientes nombran tradicionalmente con el lenguaje y los signos no lingüísticos, por el otro, lo que denominan los símbolos. Por nuestra parte, introduciremos un tercer polo transversal, en cierta forma, a la dualidad anterior y que está configurado por los dinamismos simbólicos. Además, conceptualizaremos el primer tándem bajo el título de función significante y haremos lo propio con los símbolos, bajo la noción de función simbolizante.

\subsection{La significación (perspectiva estructural)}

\subsubsection{Los modelos mentales}

Uno de los factores que caracterizan al lenguaje y a los signos no lingüísticos, indistintamente, es el modelo de conexión que se establece entre el polo de lo significante, al 
que llamaremos también plano de la expresión, y el polo de lo significado o plano del contenido. En el caso de los llamados símbolos, la conexión específica se establece entre el plano de lo simbolizante o lo evocante y el plano de lo simbolizado o lo evocado.

Ahora bien, el sentido de las expresiones polo del significante y del significado, de lo simbolizante y lo simbolizado, se entienden con mayor claridad cuando se enfocan desde lo que Klinkenberg (2006) caracteriza como "modelos mentales" -de estirpe kantiana-, cuya función consiste en organizar los datos proporcionados por la experiencia. Las citadas expresiones, por tanto, hacen referencia a los conceptos que intervienen en el armado teórico, en el cual consisten las realidades mentales a las que se nombra con las palabras, los signos y los símbolos. Al mismo tiempo, estos modelos tienen un correlato particular en el campo de lo directamente perceptible por los sentidos. De este modo, al polo del significante corresponde el stimulus y al del significado, el referente. Ahora bien, el haz de percepciones sensoriales que constituyen el stimulus y el referente sólo se perciben sistematizadamente, en cuanto stimulus y en cuanto referente, cuando se enfocan desde los modelos correspondientes.

En las ciencias del lenguaje se ha considerado que el acercamiento desde los "modelos" es más propio de la lingüística, mientras que la reflexión acerca del stimulus y el referente bordea los linderos en que confluyen en ésta y la filosofía. De este modo, estos términos nos ubican dentro los límites de los temas centrales de este escrito.

La presencia del elemento caracterizado como stimulus propuesto por Klinkenberg adquiere relevancia, sobre todo en el contexto de la función comunicativa que, inseparable de la función de significación pero no en viceversa, cumplen el lenguaje, los signos y los símbolos.

\subsubsection{Semejanzas y diferencias}

Un primer fenómeno que marca la diferencia entre la función significante y la función simbolizante se ubica en la asunción teórica de lo sensorialmente perceptible, específicamente, el stimulus: en el caso de la función significantepalabra el correlato sensorialmente perceptible del plano de la expresión es el conjunto articulado de sonidos que configuran el sustrato material del lenguaje. En contraste con lo anterior, en la conexión que se establece entre el plano de lo simbolizante y de lo simbolizado, dicho stimulus es representado prácticamente por cualquier otra cosa. 
En cuanto al tema del referente -siempre según el sentido definido por Klinkenberg-, la función significante y la función simbolizante comparten una condición común. En este polo pueden ubicarse, prácticamente, todo género de realidades, incluidos aspectos de la interioridad psíquica de las personas como sentimientos, actitudes, entre otros, así como entidades fantásticas - aquellas que son consideradas sobrenaturales o divinas.

Por lo que toca a la corporalidad implicada en la función significante, si nos situamos en el polo de lo significante, caracterizamos el momento emitente, provisionalmente, como un conjunto de movimientos musculares a los que Zubiri (2007) hace alusión. Este autor explica que la base corporal del fenómeno reductivo en que consiste la significación son los sonidos de fonación, los cuales emite el ser humano, prácticamente, desde que nace. Ahora bien, junto con los de la mano, esta clase de movimientos son los más formalizables. Al primer estadio de formalización -que permite una fonación en sentido estricto- se suma un segundo donde estos sonidos se emiten ya de manera articulada. De este modo, está dada la base para que estos sonidos sean no sólo expresivos sino signitivos $y$, finalmente, significativos, a través de ulteriores reducciones.
Por otro lado, hay que tener en cuenta otro factor que está dado por la corporalidad implicada en las operaciones fisiológicas correspondientes al momento recipiente. En el caso de la función significante de carácter lingüístico, la corporalidad a través de la cual se tiene acceso al fenómeno del sonido articulado es de carácter acústico. Por el contrario, cuando se trata de la función simbolizante, la corporalidad que queda comprometida es de naturaleza ocular.

Por su parte, en términos generales, el plano de la expresión -en el caso del lenguaje y los signos no-lingüísticos- está constituido por representaciones de naturaleza auditiva y por imágenes mentales de carácter visual, respectivamente. Éstas últimas son centrales también cuanto se trata de los símbolos. En el plano del contenido, en todos los casos, además de contemplarse estas mismas posibilidades puede encontrarse también elementos de carácter conceptual.

En cuanto a la diferencia que existe entre la función significante y la función simbolizante, por lo que toca al carácter mismo de la remitencia, hay que decir que el vínculo que relaciona el polo de lo significante con el polo de lo significado, en el caso de la primera, es de carácter convencional, esto se debe al acuerdo, explícito o implícito, al que ha llegado una colectividad. 
En el caso de la segunda función, la posibilidad de vincular ambos conjuntos descansa en el hecho de que alguno o algunos de los rasgos organolépticos de las entidades del polo de lo remitente guardan cierta relación con los rasgos - tanto organolépticos como psíquicos o morales- estructurados en el polo de lo evocado; sin que esto, por lo demás, excluya la eventualidad de un acuerdo por parte de los usuarios.

El modelo de remitencia
convencional tiene romo consecuencia que los elementos que configuran el polo de lo significante sean algo meramente transitivo, su involucración en las funciones significantes opera en cuanto dirigen la atención hacia el polo de lo significado y no hacia sí mismos. En este sentido, la intelección de las notas que configuran a los sonidos situados en el plano de la expresión, en cuanto elementos pertenecientes a este plano, tiene como función directa la puesta en marcha de la convención, no de la remitencia directamente hablando, sino que ésta sólo ocurre a través de la actualización de la convención. Ciertamente, la mencionada intelección es un condicionante para esta actualización de la convención $y$, a través de ésta, para la remitencia misma; esto es lo que llamamos la transitividad del polo de lo significante.
Finalmente, la conexión que se establece entre los polos o planos se ubica en el contexto del sistema en que consiste en último término una lengua o el acervo simbólico de un grupo humano. Este aspecto fue conceptualizado, sobre todo para el caso del lenguaje, a través de la categoría de forma, tanto por Saussure (1982), como por Hjemslev (1971), si bien con matices diferentes. A su vez, los sistemas lingüístico y simbólico operan en un contexto cultural y social determinado.

\subsection{La comunicación (perspectiva procesual)}

La función significante y la función simbolizante desempeñan -inseparablemente del cometido de la significación- una labor comunicativa. Pues bien, este cometido en cuanto representa un proceso a lo largo de un eje temporal, implica varios momentos en los que intervienen diferentes actores y funciones. Para los fines del presente trabajo es suficiente con enunciar sucintamente la naturaleza de cada uno de ellos.

El desarrollo de la acción comunicativa implica-parafraseando a Jakobson- seis célebres funciones, a saber: referencial, emotiva, connotativa, poética 0 estética, fática y metalingüística. A partir de esta formulación pionera, e inspirados también en los modelos relacionados con las teorías de 
Weaver y Shannon (1948), así como de Berlo (2008), veremos en qué consisten los momentos que, en las anteriores propuestas, constituyen uno de los ejes en torno a los cuales se estructuran dichas funciones: el momento emitente y el recipiente.

En relación con lo anterior, téngase en cuenta que Saussure había formulado la teoría del "circuito del habla", según la cual éste se encuentra configurado por dos segmentos: el primero corresponde a la emisión de la palabra y el segundo a la recepción de la misma. En ambos segmentos actúa una serie de elementos y procesos que Saussure agrupa bajo tres categorías: lo "psíquico", lo "fisiológico" y lo "físico".

El momento emitente representa, en cierto modo, la parte inicial del proceso de la comunicación, en la que actúa la fuente de la misma en expresión de Shannon (1948)-, a saber, la entidad que produce el mensaje o una secuencia de mensajes para ser comunicados a la terminal recipiente. Según Berlo (Citado en Barba y Cabrera, 2003), en el momento emitente, el emisor del proceso comunicativo opera a través de tres pasos: el desarrollo de una idea, la codificación de la misma y su transmisión. En este contexto, si aplicamos la teoría saussureana del circuito del habla, el momento emitente es aquél que inicia con un conjunto de operaciones de naturaleza psíquica, las cuales producen finalmente un fenómeno físico, a través de un conjunto de operaciones de carácter fisiológico. En este escrito entenderemos por momento emitente aquél en que un acto humano o de un dispositivo cualquiera da origen, de manera empíricamente perceptible, a una entidad significativa. De este modo, esta noción sólo es aplicable al lenguaje y a determinados tipos de signos y de símbolos.

A su vez, en el momento recipiente interviene el destino (“destination"), a decir de Shannon, a saber, la persona a la cual ha sido dirigido el mensaje. Siguiendo el mismo esquema elaborado por Berlo, hay que decir que en este momento recibe el mensaje, lo descodifica, lo acepta y lo utiliza. Si aplicamos en este momento el circuito del habla saussureano; a la secuencia que corresponde al momento emitente el autor añade un segundo segmento que la prolonga, el cual parte de un proceso físico. Éste dispara, a su vez, un evento de carácter fisiológico y desemboca, finalmente, en una operación de naturaleza mental o psíquica.

Para los fines del presente texto es suficiente con esta somera caracterización. 


\section{Acercamiento, en contexto noológico, a los momentos emitente y recipiente de las funciones}

\section{Preliminares}

En los párrafos que vienen a continuación presentaremos la manera como Zubiri explica lo que entiende por "palabra" y por "señal". El objetivo de este ejercicio es poder profundizar en la naturaleza de lo que hemos venido llamando la función significante y la función simbolizante, pero para lograr esto habrá que llevar a cabo, posteriormente, una labor de interpretación y una adaptación - de carácter hipotético- de los desarrollos de este autor.

Es importante tener presente que las explicaciones estrictamente zubirianas -que reseñaremos a continuación- acerca de la palabra y la señal se desarrollan solamente en un contexto de carácter noológico, con ello queremos dar a entender que no se trata de caracterizaciones estrictamente noológicas acerca de la naturaleza de estas expresiones del ser humano. Más adelante quedará claro por qué hacemos esta advertencia.

De entrada, vemos un primer contraste entre la explicación que aporta Zubiri a propósito de la naturaleza de la "palabra" y aquella en la que da razón de la "señal". En el caso de la primera, la palabra aparece ubicada en el momento emitente, sin que esto signifique que la explicación sólo sea válida con respecto a este momento, como veremos posteriormente. En claro contraste, en la explicación de la naturaleza de la señal, ésta aparece ubicada en el contexto del momento recipiente.

En este contexto es necesario tener presente que no se da una coincidencia punto por punto entre lo que Zubiri denomina la palabra y la señal, por un lado, y lo que nosotros hemos caracterizado como la función significante y la función simbolizante, por otro. Esto sucede, entre otras cosas, porque no describió la manera como la señal apunta -como veremos posteriormente-. De este modo, lo que Zubiri llama la palabra cae, ciertamente, bajo el concepto de la función significante, pero ésta, a su vez, en la acepción de función significante-cosa, podría incluir también lo que Zubiri denomina señal. Por otro lado, esta última expresión podría abarcar lo que hemos denominado función simbolizante. Para evitar confusiones, y para los fines y los límites del presente trabajo, traduciremos las expresiones zubirianas lenguaje 0 palabra como función significantepalabra o, simplemente, como función significante y cuando empleemos la expresión zubiriana 
señal, la restringiremos al concepto de función simbolizante.

\subsection{El lenguaje y la señal en los términos de Zubiri}

\subsubsection{El lenguaje como fenómeno de significación}

Zubiri (1991, p. 50) sostiene que el lenguaje está formado por "algunos sonidos [no todos]" a los que se le añade la "significación". El autor añade que la forma en que ésta última se agrega a los primeros no es algo a tratar en ese momento; ello sucede "en la forma que fuere", aclara. Con esto, el autor rinde homenaje al legado aristotélico, en el cual el lenguaje es comprendido como phoné semantiké. Pues bien, a partir de este lacónico enunciado surgen dos cuestiones: la primera se refiere a la forma en que la significación se añade a los sonidos, la segunda remite al sentido que tiene -en el pensamiento del último Zubiri- el mismo término significación.

Aclaremos desde este momento que la primera cuestión tiene, ante todo, un talante lingüístico. No obstante, también es posible enfocarla desde la perspectiva de la antropología zubiriana, pero no entraremos en este planteamiento. La segunda cuestión, a su vez, será respondida, en parte, un poco más adelante. A propósito, cuando esto suceda, observaremos que esta explicación valdrá cuando entendamos el vocablo expresión -en su acepción antropológica- in actu exercito, y cuando consideremos la función significante situada en el momento de la emisión. En cualquier caso, la pregunta sólo quedará solventada en su totalidad en la posterior explicación hipotética de carácter noológico.

De entrada, lingüísticamente se puede confirmar la primera parte de la afirmación zubiriana, en el sentido de que se trata de cierta clase de sonidos -él mismo, como hemos visto, había indicado que se trata de sonidos articulados (Zubiri, 2007)-, a los que se añade la significación, por lo demás, ya se sabe que sobre este hecho estriba una de las diferencias fundamentales, clásica en la lingüística, entre los llamados fonemas y morfemas.

\subsubsection{El signo como señal}

Otro vector de la comunicación cuya identidad explica de manera enunciativa el autor es lo que nombra la "señal". Pues bien, Zubiri (1991) sostiene que lo característico de las señales es que su contenido "es aprehendido por sí mismo y 'además', por tanto, extrínsecamente, 'señaliza'” (pp. 49-50). Entre los referentes concretos de ese vocablo cita las señales de tráfico o de humo. 
En este caso, lo primero que constatamos es que la explicación que ofrece Zubiri supone ubicadas a las "señales" en lo que hemos nombrado el momento recipiente, a la inversa de lo que sucedió con la función significante.

Es importante señalar también que esta explicación que ofrece nuestro autor se ubica en el contexto de su exposición acerca de la signitividad -en el sentido que maneja este término, diferente del que proponemos en este escrito$y$, por tanto, en el contexto de la aprehensión de realidad. Por lo mismo, su pretensión fundamental no consiste en desarrollar ampliamente estas nociones, sino contraponer la señal al signo, con el objetivo de aclarar más la naturaleza de este último. Nosotros estamos procediendo de otra manera; lo que buscamos es aclarar, noológicamente, lo que significa la función significante y la función simbolizante, como dos formas diferentes del funcionamiento del fenómeno de la significación. Más adelante volveremos sobre este punto.

\subsection{Las funciones en el contexto de la aprehensión primordial}

Mostraremos ahora la manera como algunos de los elementos de la noología zubiriana contribuyen a profundizar las concepciones lingüísticas y simbológicas. En esta parte del trabajo veremos sólo dos modos del hecho intelectivo: la aprehensión primordial y la aprehensión dual. El modo propio de la marcha de la razón se verá posteriormente.

\subsubsection{Unidad de sentir e inteligir}

En su análisis de la aprehensión primordial, Zubiri aporta una clave decisiva para nuestras disquisiciones: el inteligir sentiente no consiste en dos actos, como se había conceptuado anteriormente -sentir y entender-, sino se comprueba que se trata de un mismo y único acto que por ello, propiamente, se debe llamar inteligencia sentiente o sentir intelectivo.

La manera de "habérselas" de los seres humanos con la realidad -su habitud radical, la cual no depende, como en el caso del contenido, de los sensores, pero sí de la estructura de notas- hace que la impresión provista por los sentidos "quede" de un modo específico; por lo cual dichos datos no constituyen un mero prolegómeno a un acto diferente que sería la intelección. Digamos que Inteligir es una forma de sentir; no otro acto, numéricamente hablando, que ocurriría pos y propter esa operación. Por eso mismo, las operaciones psíquicas relativas a la percepción de los elementos que configuran el polo de lo significante, en términos de la lingüística clásica, configuran un evento de aprehensión primordial, en el contexto de la 
aprehensión dual, lo explicaremos después. Por lo tanto, no se pueden entender como un hecho de carácter únicamente sensorial -como aparecía en esa disciplina-. Más bien, en dicha percepción se da un acto de intelección por el que quedamos plantados en la realidad. De este modo, la unicidad del acto de inteligir, en la explicación de Zubiri, anula la concepción dualista de la lingüística clásica, ya que en los niveles radicales no se puede hablar de una abstracción inteligible a la que se accede, merced al fenómeno de la significación, a partir de los elementos que configuran el ámbito de lo meramente sensorial.

\subsubsection{Los modos de "presentación" de la realidad y las funciones conectivas}

El análisis de la aprehensión primordial comprende otros planteamientos que resultan decisivos para comprender la naturaleza y la diferencia entre la función significante y la función simbolizante. A partir de lo mismo, Zubiri (1991) colige que "como cada sentido me presenta la realidad en forma distinta, resulta que hay diversos modos de impresión de realidad" (pp. 100). Analicemos, pues, cómo afecta esto a la comprensión lingüística o semiológica de la función significante o la función simbolizante.

\section{La función significante}

En cuanto a la comprensión lingüística de la función significantepalabra, la explicación de la aprehensión primordial contribuye a clarificar dos cosas: la primera tiene que ver con la cosa física que, como stimulus, constituye el sustrato material del plano de la expresión; la segunda remite a la forma como se establece la conexión entre dicho plano y el del contenido.

En cuanto a lo primero, la cosa acerca de la cual el oído notifica es la persona que, en el momento emitente, pronuncia la palabra o discurso registrado por dicho oído notificante. De este modo se establece una distinción entre la cosa ubicada en el plano de lo significante y la cosa acerca de la cual el oído notifica en el momento recipiente. Esto contrasta con lo que sucede en la función simbolizante; aquí lo que la vista hace presente en el caso del polo de lo simbolizante es la cosa misma que se encuentra ubicada en este polo.

En cuanto a lo segundo, lingüísticamente hablando -como ya sabemos-, la conexión que opera entre el plano de la expresión y el plano del contenido es de naturaleza convencional. Pues bien, lo que percibimos es que se da una correspondencia entre este enfoque de carácter lingüístico y la perspectiva propiamente noológica; entre la 
convencionalidad, por un lado y, por otro, el hecho de que sean el oído y el sonido los factores privilegiados de la misma, y que la labor que cumplen sea de carácter notificante. Veamos esto más despacio.

Por el lado de la función significante, el carácter convencional del vínculo elimina el papel que podrían desarrollar directamente los elementos de carácter organoléptico del plano de lo significante en relación con el establecimiento de la conexión remitente con los elementos del plano de lo significado. En este sentido, los elementos situados en el plano de lo significante deben encontrarse en un segundo plano y, con ello, se realza el papel del factor humano. Esto queda refrendado por la perspectiva propia de la función comunicativa.

Ahora bien, noológicamente hablando, se da una convergencia con el anterior razonamiento puesto que Zubiri, en la explicación que ofrece acerca de la labor notificante del sentido del oído, el término al que apunta dicha notificación no es el sonido físico que, lingüísticamente, constituye el soporte de la función significante, sino la persona que a través de dicho sonido se hace presente, notificadamente, para el sujeto de dicha audición; el sonido no puede ser lo notificado puesto que lo real del sonido es el modo de presentación notificante.
Esta convergencia se explica porque, en la consideración del modo de presentación de la realidad propio del sentido del oído, Zubiri no está manejando la experiencia que se tiene en la audición de las palabras, sino de los sonidos, en sentido genérico; lo cual viene a recalcar que, en el caso de las primeras, se trata de sonidos de naturaleza muy específica, como el mismo autor había ya reconocido: se trata de un fenómeno acústico portador de significado. Ahora bien, en último término esta especificidad de la palabra viene dada únicamente por el productor humano de la misma.

Vemos, entonces, que el fenómeno de la palabra, no sólo como portadora de significado sino como una mera cosa, remite al factor humano que se encuentra en su origen. En este sentido, entendemos que la convergencia de los argumentos apunta a la afirmación última a la que conduce el razonamiento lingüístico; pero no se trata, propiamente, de una demostración de carácter noológico.

Antropológicamente -en el enfoque zubiriano- se refuerzan las anteriores consideraciones. Finalmente, la palabra es - antes que una phoné semantiké- expresión de un ser humano (Zubiri, 2007). De este modo, se cierra el círculo reflexivo: el lenguaje, dice Zubiri, en la experiencia cotidiana pone en contacto no sólo con sonidos o significados, sino con personas. 


\section{La función simbolizante}

En el caso de la función simbolizante, el momento de la recepción corresponde, normalmente, al sentido de la vista. A través de ésta, como hemos observado, la cosa misma que se sitúa en el plano de lo simbolizante se hace presente, ella misma según su eidos, ante el observador.

Ahora bien, esta explicación ayuda a profundizar la comprensión de carácter simbológico de la función simbolizante, igual que en el caso de la función significante. Lo primero a considerar es la forma como se resuelve la distinción entre lo que se hace presente a través del modo de presentación de la realidad propio del sentido de la vista y los elementos que se sitúan en el plano de lo simbolizante. Como habíamos adelantado, a diferencia de la función significante, en este caso se trata de la misma cosa y, por tanto, cesa la distinción que caracterizaba a aquélla.

En segundo lugar, veamos si se da cierta correspondencia entre la forma de conexión que se establece entre lo situado en el polo de lo simbolizante y lo situado en el polo de lo simbolizado, por un lado y, por otro, el cometido - propio de la vista- de poner "delante" a la cosa, "según su eidos".
Pues bien, lo que constatamos es que sí se da tal correspondencia, y ello contribuye a profundizar la intelección de esta función. Como hemos visto, en la función simbolizante, la función conectiva se establece de manera motivada, esto es, por cierto tipo de relación que se establece entre los rasgos organolépticos de los elementos situados en el eje de lo simbolizante y los de lo simbolizado. De este modo, las cosas mismas implicadas en la conexión cumplen un papel definitorio en este género de conexión. Ello no significa que, finalmente, la función simbolizante no cumpla una función de comunicación y comunión entre personas y que esto sea lo definitivo, sino que las personas que utilizan esta forma de comunicación se expresan, precisamente, a través de los citados rasgos y a través de la conexión que se establece -a partir de los mismos- con el polo de lo simbolizado.

De este modo, lo anteriormente dicho acerca de la función significante y de la función simbolizante va a tener consecuencias cuando se proponga una hipótesis estrictamente noológica acerca del funcionamiento de ambas.

\subsection{Las funciones en el contexto de la aprehensión dual}

Un primer tema que conviene mencionar -aunque sea de forma enunciativa-, por la trascendencia 
que presenta para el conjunto $\mathrm{y}$, sobre todo, para los objetivos de esta reflexión, está conectado con el análisis que realiza Zubiri acerca de la simple aprehensión y el papel que desempeñan en la misma los perceptos y los fictos. Por esta vía es posible sopesar el valor que poseen las representaciones de naturaleza icónica y simbólica -en suma, imaginativa-, para la intelección y la comprensión de la realidad. De este modo, se posibilita ubicar en sus justas proporciones la contribución propia del entramado de carácter conceptual que caracteriza al conjunto de los conocimientos científicos -tema que presenta fuertes matices contraculturales-.

\subsubsection{La palabra como "expresión de realización"}

En la investigación que sacó adelante Zubiri acerca de la intelección dual, ésta aparece explícitamente conectada con la emisión de palabras. La mención, a propósito de las "formas" de la afirmación es, al parecer, un auténtico hápax legomenon zubiriano. Recordemos la frase fundamental:

El juicio es ante todo lo que llamo una afirmación posicional. Comencemos por poner algunos ejemplos. Abro la ventana y exclamo: “Fuego!", o bien digo simplemente, "lluvia, sol”, etc. (Zubiri, 1982, p. 162)

Hay que recordar que el juicio posicional es la primera forma de afirmación que consigna el filósofo. Ésta consiste a diferencia de las otras dos (proposicional y predicativa) en que aquello de que se afirma algo -en el caso que acabamos de mencionar: aquello que percibo al abrir la ventana - no es algo que haya sido aprehendido ya a través de una aprehensión dual precedente, sino solamente a través de la aprehensión primordial de realidad. Por tanto, aún no es algo aprehendido según lo que es en realidad, sino simplemente aprehendido como algo "en propio", algo "de suyo", con todas sus notas, pero hasta ahí.
En esta clase de juicios lo que se afirma es la realización de lo simplemente aprehendido, en la cosa real primordialmente aprehendida al abrir la ventana. Ahora bien, lo que hacen las palabras fuego, lluvia, sol, es "expresar" ese fenómeno de realización: “(...) expresan que lo simplemente aprehendido se realiza en lo que he aprehendido primordialmente, y es lo que éste es en realidad". El autor acota también el fenómeno de la significación en cuanto algo propio "tan sólo" del lenguaje, con lo que se produce un descarte con respecto a los signos no lingüísticos y los símbolos (Zubiri, 1991, p. 50). Todo lo cual parece 
indicar - provisionalmente hasta este momento- que la expresión, a través de la palabra, del fenómeno de realización de la simple aprehensión, en este caso, en el corazón de un juicio posicional es a lo que nuestro autor nombra la significación.

Ahora bien, en este caso, el tipo de palabra que desempeña el rol de expresión de realización, según Zubiri, es el "nombre", pero esto bajo ciertas condiciones. En primer lugar, se trata de un nombre o sustantivo que, además, es el único elemento gramatical que interviene en tal juicio, a diferencia de lo que sucede en el juicio proposicional, como veremos después. Además, no se trata de la pronunciación de un sonido, entendida en términos abstractos, sino que la inflexión de la voz resulta determinante, pues a través de ella se exterioriza la "connotación afirmativa". A este respecto afirma el autor: "El momento afirmativo de este juicio (se expresa) con un solo nombre en connotación afirmativa. Y esta connotación se expresa en la entonación,por ejemplo,exclamativa" (Zubiri, 1982, p. 154). Esto se confirma, por contraste, a través de otra precisión que ofrece Zubiri, en la que aclara que la manera como se expresa la simple aprehensión es a través de meros nombres, esto es, sin connotación afirmativa: "Estos nombres (fuego, lluvia), como meros nombres, son simples aprehensiones" (Zubiri, 1982, p. 182). De este modo, la forma de expresarse resulta determinante en la utilización de la palabra en relación con el fenómeno noológico de la realización de una simple aprehensión. Vemos cómo convergen aquí la antropología y la noología zubiriana, lo cual reafirma que no es posible comprender la función propia de la palabra y los símbolos sin incorporar la perspectiva antropológica y, por tanto, social.

En este contexto hay que tener en cuenta también que la palabra no puede entenderse como una expresión de realización, únicamente en el contexto de un juicio posicional, puesto que se encuentra esencialmente referida a la realización de una idea en lo real, lo cual resulta determinante también en los llamados juicios proposicionales y predicativos, aunque en este caso esto suceda de manera diferente. De este modo, en los primeros, la expresión se plasma en palabras que se encuadran en conjuntos orgánicos, gramaticalmente regulados; Zubiri los caracteriza como frases nominales. Así lo explicita cuando advierte que, dado que se encuentran caracterizados por la unidad de complexión de los tres momentos de la posición de "B" en "A", su expresión propia consiste en frases que, por un lado, carecen de un vocablo de carácter verbal, pero por otro lado, cuentan al menos con dos nombres. Los cuales, por cierto, ponen de manifiesto una sola realidad complexiva; la pausa característica de una frase nominal 
es la expresión propia de esta afirmación complexiva (Zubiri, 1982, pp. 157-158).

A su vez, los juicios predicativos se caracterizan no por la complexión, sino por la unidad de conexión. Ello se expresa, en contraste con lo anterior, a través de formas verbales, las cuales significan, por un lado, la unidad conectiva entre los polos implicados y lo que el primero es en realidad ("función de unidad conectiva") y, por otro, la realidad de dicha conexión ("función de realidad"). En el caso del verbo ser, la expresión reviste un carácter particular, pues, junto con manifestar todo lo anterior en cuanto verbo sustantivo que es -al igual en esto que los demás-, designa también la relación misma que se establece, por ello adquiere una función de carácter copulativo. Por todo lo cual se ve que ésta última función se apoya en las anteriores, que son las determinantes, y no viceversa (Zubiri, 1982, pp. 165-168).

Finalmente, la vocación de la palabra no puede quedar circunscrita a la intelección dual ni, por tanto, funcionar como expresión de un fenómeno de realización en esta modalidad. Cuando Zubiri expone el concepto de sistema de referencia en la explicación del método -en el contexto de la marcha de la razónse cuida de establecer que éste "envuelve" ciertamente un conjunto sistemático de representaciones, en cuanto "las cosas campales están ya "presentes". Sin embargo, la función propia del sistema de referencia no es formalmente representativa. Al respecto no hay que olvidar que las representaciones desempeñan una función doble: una propiamente representativa y otra de carácter direccional; la segunda es la que las constituye en sistema de referencia. De este modo, en la expresión de la intelección racional en que consiste el lenguaje,"no se trata de constatar la realización de las representaciones, sino de experienciar una dirección" (Zubiri, 1983, pp. 213-215). Este tema lo ha desarrollado A. González (1994) en el contexto de lo que él llama la tercera dimensión de lenguaje, basándose, a su vez, en Zubiri (2007). De este modo, explica que el lenguaje tiene una "función direccional".

En este punto, conviene recordar lo que ya habíamos adelantado: estas propuestas acerca de la naturaleza de la palabra no ofrecen una explicación estrictamente noológica, sino solamente se dan en un contexto noológico. En primer lugar, la explicación es de naturaleza más bien antropológica -por ello pensamos que Zubiri emplea el término "expresión"-, y desde aquí sirve como complemento para la explicación noológica de las funciones significante y simbolizante a partir de la intelección dual y el conocimiento; desde aquí también se aclara la función que cumplen los sustantivos, las frases y los verbos. 
En segundo lugar, hace falta todavía explicar lo que significa la segunda parte de la fórmula - "de realización"-, en este contexto específico de la función significante. ¿Qué implica todo esto, zubirianamente hablando?

En primer lugar, a causa del carácter de expresión propio del lenguaje, se refuerza la convicción, ahora desde el enfoque de que éste se encuentra enraizado en la realidad: se trata de la hexis de convivencia. De este modo, la realidad humana se encuentra vertida a los demás; en eso consiste el "ser de suyo las demás personas". Por lo cual, constatamos que el ser expresión emerge desde la socialidad, arraigada a su vez en la estructura sustantiva de los seres humanos en su realidad.

Al respecto, A. González, refiriéndose a la habituación a través de la cual determinados sonidos se articulan mediante la intervención de los demás, afirma:

$Y$, en segundo lugar, esta habituación tiene un momento intelectivo según el cual los sonidos articulados son inteligidos como señales. Pues bien, el momento intelectivo de las señales fonéticas no es otro que el logos. Se trata, por tanto, de una reducción como distanciamiento hacia unas simples aprehensiones y de un intentum reversivo hacia los sonidos que funcionan como señales. Naturalmente, estos sonidos no tienen el carácter de huellas, sino de símbolos. Y, en cuanto tales, no funcionan aislados, sino en sistema. El lenguaje aparece entonces como un sistema de señales. $Y$ este sistema de señales se sustenta en habitudes sociales. Los sistemas de señales pertenecen a mi modo de habérmelas con las cosas, en cuanto determinado por los demás. Por eso "en el lenguaje está constitutivamente presente la héxis física de la simple alteridad". (González, 1994, p. 183)

En segundo lugar, el lenguaje, como expresión de realización y como experienciación de una dirección, es algo exclusivo del mundo de la cultura. Por ello, a la aprehensión primordial no le corresponde propiamente una expresión verbal, ni siquiera en su configuración más elemental: "En la aprehensión primordial no hay nombre ninguno.
Es mera aprehensión de la realidad de lo real" (Zubiri, 1982, p. 154). La expresión verbal aparece recién, cuando lo hace también, al menos en un primer nivel, el mundo de la cultura a través de la simple aprehensión. 
2.3.2. La "señal" como...

A diferencia de lo que sucede con la palabra, la caracterización zubiriana de la señal deja más preguntas que certezas.

Hay tres temas que quedan indeterminados en la propuesta de Zubiri. En primer lugar, es válido preguntarse qué significa la referida expresión zubiriana de que "su contenido es aprehendido por sí mismo", es importante hacer esto, tanto en relación con la función simbolizante misma como también en relación con la función significante - como hemos comenzado a hacerlo más arriba-. De este modo, hablando más acotadamente, estamos tratando de averiguar qué tanto, cuando él habla de una aprehensión, se refiere a la aprehensión primordial -el caso, por ejemplo, de las afirmaciones posicionales- o si se refiere, más bien, a las otras formas que reviste la afirmación. Otra manera de formular la misma cuestión es preguntando si existe algún momento de la explicación noológica de la función simbolizante en el que interviene un juicio de carácter posicional y si se involucran también, y en qué momento, juicios proposicionales o predicativos.

En segundo lugar, lo decisivo en este tema es la interrogación acerca de qué significa la expresión "señalizar" -como lo hemos hecho en el caso de la "significación"-.
Pues bien, para comprender mejor el funcionamiento de la función simbolizante ayudará preguntarnos también por la intervención de los aspectos sociales en la misma, más específicamente, el papel de la cultura. Más adelante trataremos de elaborar una respuesta a estas cuestiones, desde una perspectiva noológica, lo haremos por nuestra cuenta y riesgo, y de manera hipotética.

\section{Inconclusión}

Con lo que hemos estado viendo hasta este momento quedan contextualizadas las afirmaciones que había lanzado Zubiri acerca de la palabra y la señal en el momento de la emisión. Simultáneamente, aparecen en el horizonte varias cuestiones por solventar.

La palabra, lo hemos visto, no es más que una expresión del momento de afirmación propio del logos. Ahora bien, la pregunta que hay que responder en este caso es: ¿qué es lo simplemente aprehendido? ¿Es "idea" de qué?

En cuanto a la explicación de la señal, es claro que se trata también del momento de afirmación -noológicamente hablando- y que tiene que ver, ante todo, con la cosa que "señaliza" -el polo de lo simbolizante, en términos simbológicos-. Pero queda pendiente 
la pregunta acerca de cómo se da la conexión, desde la primera perspectiva, entre esas cosas que señalan y las que son señaladas. Con la respuesta que se pueda dar a esta cuestión quedan puestas las bases para aclarar noológicamente lo que sucede en el momento recipiente. Finalmente, esta explicación llevará a cabo la unificación de todo el conjunto; lo que sucede en el momento de emisión y en el de recepción.

\section{Estatuto noológico (parazubiriano e hipotético)}

\subsection{La función significante}

\subsubsection{Preliminares}

Ante todo, en relación con la expresión "parazubiriano", hay que aclarar que el filósofo vasco no propone directamente la explicación noológica, que se desarrollará en los párrafos subsecuentes, relativa a las funciones significante $y$ simbolizante; se trata, en todo caso, de elaboraciones propuestas por el autor del presente escrito, que están fundamentadas, eso sí, en aspectos de la noología de Zubiri que se han venido comentando hasta este momento.

Entrando ya en el tema del enfoque noológico, para que podamos ofrecer una explicación viable de las funciones significante y simbólica es necesario relacionar la explicación que ofrece Zubiri acerca del papel de la palabra en el momento que hemos nombrado la emisión, con el momento de la recepción de la misma. Pero, para que esto funcione, hemos de aplicar también la observación acerca del contenido de la señal, aunque no de manera totalmente simétrica. Esto se debe a que, si bien, en el caso de la palabra el contenido es aprehendido también por sí mismo, sin embargo, no tiene por qué serlo en la misma forma en la que es aprehendido en el caso, por ejemplo, de la función simbolizante, tal como se explicará posteriormente.

Habíamos visto ya que, si queremos comprender, en términos noológicos, la función que cumplen uno o dos nombres, o un verbo, pronunciados en el momento emitente de la función significante, hay que caracterizar dicha función como una expresión de realización, esto es, como la expresión de que una idea -simplemente aprehendida- se ha realizado en una cosa real. En este sentido, hablando lingüísticamente, una palabra cualquiera, involucrada en una función significante, tiene como último referente una cosa real; esto implica también que no tiene sentido en sí misma, sino en relación con dicha función. Hasta aquí el enfoque filosófico es claro. 
Ahora bien, hace falta analizar, también desde una perspectiva noológica, cómo se comporta la función significante en el momento recipiente. Al respecto, lo primero que hay que decir es que el proceso que parte de la escucha de un nombre o de una expresión más amplia en la que se encuentran implicadas formas verbales, y culmina en una remisión que apunta al plano de lo significado, implica la intelección de esos primeros elementos lingüísticos, también como una expresión de realización. Pero ¿en qué sentido se puede entender esto? sobre todo, tomando como punto de partida la perspectiva lingüística que acabamos de mencionar.

\subsubsection{La palabra como realización de expresión}

Lo primero que hay que decir, noológicamente, es que la recepción en el contexto de una función significante tiene lugar al interior de la estructura típica de la intelección dual, pues, en principio, no es más que la intelección de lo que algo es en realidad. En segundo lugar, todo lo que llevamos dicho sugiere también que la intelección campal en que consiste, noológicamente hablando, la función significante debe explicarse desde el análisis de la aprehensión primordial, en el caso de que incluya una captación del stimulus. Por lo cual, en el conjunto, dicha intelección campal debería tener la estructura de un juicio posicional. De este modo, este hecho es lo que quedaría expresado a través de la afirmación, tomada y adaptada de la noología zubiriana, de que el contenido de una palabra es "aprehendido por sí mismo", aquí se encuentra la semejanza con la señal, pero también la diferencia, como veremos enseguida. En este contexto, las explicaciones que ofrece Pintor Ramos (1987, pp. 119 ss. y 130) ayudan a situar mejor este punto de vista.

Esta consideración noológica converge, en cierto modo, con el acercamiento lingüístico. Para Ricoeur (1990), (siguiendo en esto a Saussure) el significante no está constituido por el concepto de la palabra en cuestión, sino por una representación de la misma de carácter acústico. De este modo, el acto de significación $y$, correspondientemente, de comunicación, no culmina con la captación perceptiva de la palabra misma -a través de su concepto, según la epistemología subyacente en estos autores-, sino que está conectado con una percepción mental de carácter conceptual, inducida por el significante, la cual representa al referente de la palabra.

En tercer lugar, si bien hay que caracterizar a la función significante, en el momento emitente, como expresión de realización, en el cierre del proceso de recepción debería ser identificada, en cierto modo, como realización de expresión. 
La explicación noológica de esto implica que, en lo que Zubiri nombra la primera fase del movimiento intelectivo dual, la "idea" de una palabra particular, con la que se conecta -en virtud de una habitud de carácter social- la expresión de la realización de alguna simple aprehensión, se realiza libremente en "la" realidad, como principio intelectivo de lo que tal sonido articulado, aprehendido previamente en aprehensión primordial, "sería" en realidad. En la segunda fase, lo que se afirma es la realización de esa "idea" en ese sonido articulado, aprehendido en aprehensión primordial. Como fenómeno de significación, podríamos nombrar a esto significación recipiente (en contraposición a la ya revisada significación emitente).

Esta explicación de la función significante como realización de expresión no pretende eludir el carácter complejo propio de las aprehensiones duales correspondiente al momento emitente, en los casos en que quedan implicados juicios proposicionales o predicativos, como hemos visto anteriormente; pero debe quedar claro que el momento recipiente se construye sobre juicios posicionales. En todo caso, dicho carácter complejo está conectado con las simples aprehensiones implicadas en estos juicios.
A lo anterior hay que agregar, en cuarto lugar, que si en la intelección dual la función significante opera también como expresión de realización en el momento recipiente - merced a la mencionada habitud social-, ello implica que cumple también una función en la intelección de la modalidad del conocimiento -en sentido zubiriano-, es decir, en la intelección en profundidad. Ya hemos hecho una alusión a este tema anteriormente.

Aventuramos también la posibilidad de que a esta complicación que implica la función significante en el momento que lingüísticamente llamamos la recepción - la expresión de una realización a través de la realización de dicha expresión- es a lo que Zubiri denomina significación $y$, ciertamente, es un fenómeno exclusivo de aquélla. Dicho de otra manera, a través de la función significante las personas se ponen en contacto con los procesos intelectivos de otra persona y, a través de ellos, con el mundo de las cosas-sentido. De este modo, se acentúa la función comunicativa del lenguaje.

Finalmente, hay que tener presente que Pintor Ramos (1987) pone de relieve el carácter sistemático del lenguaje, afirmación que tiene un fuerte soporte desde el enfoque lingüístico, como ya hemos visto antes. Para este autor, este rasgo deriva de la naturaleza sistemática de la intelección dual: 
Este distanciamiento de la individualidad de la cosa real hace que las palabras del lenguaje no signifiquen tan sólo por ser representación simbólica de las cosas reales; significan en cuanto la cosa significada está en un campo, en cuanto la "coherencia" (Zubiri, 1991, p. 206) originaria de sus notas se actualiza en su respectividad comunicando su realidad con la de otras cosas y formando así un sistema. Ninguna palabra aislada significa; sólo lo hace dentro de un sistema estructural (...). (Pintor Ramos, 1987, p. 120)

\subsection{Función simbolizante}

\subsubsection{Preliminares}

Si volteamos hacia la función simbolizante, en busca de una explicación noológica acerca de su naturaleza, veremos que las cosas van a funcionar de manera diferente de lo que hemos observado en el caso de la función significante.

Lo primero que hay que tener en cuenta, como punto de partida, es la aproximación simbológica que hemos ensayado anteriormente, según la cual, en el polo de lo simbolizante se encuentran situadas cosas en general, pero no sonidos articulados de carácter verbal. Correspondientemente, debió quedar claro también que la corporalidad comprometida en este modelo de funcionamiento simbólico es de carácter ocular.

Desde este enfoque previo y para proceder, ahora sí, noológicamente, ayuda echar mano de la explicación zubiriana de la unidad conectiva en la realidad -en la que consiste la afirmación- Esta disposición es lo que introduce una primera separación entre la naturaleza de la función significante y la de la función simbolizante. Lo que sucede finalmente es que en ésta última asistimos a la realización de una cosa sin más, esto es, de la "idea" de la misma.

En segundo lugar, volviendo al flanco simbológico, advertimos que el nexo que se establece entre los elementos que configuran los planos de lo simbolizante y lo simbolizado se rige por las leyes, por ejemplo, de la semejanza, el contraste o la contigüidad de carácter físico -a diferencia de los principios de identidad, no-contradicción y tercero excluido (Corcoran, 1999)-, pero igual pueden funcionar otros modelos de asociación emparentados con los anteriores. Ricoeur (1990, pp. 19, 31-32) se refiere a la relación de semejanza y la analiza, primero, desde su teoría del símbolo y el "conflicto de interpretaciones". Posteriormente, incluye una perspectiva lingüística, en la que desempeña un papel central la metáfora (Ricoeur, 1995). 


\subsubsection{Función simbolizante y afirmación}

De este modo, desembocamos propiamente en la naturaleza de la función simbolizante, la cual queda finamente expresada si partimos de las tres posibilidades que reporta Zubiri en el momento en que está explicando en qué consiste la aprehensión dual:

\begin{abstract}
Se intelige entonces que aquella cosa de la que queremos inteligir lo que es en realidad, es igual, semejante o distinta de la primera y de la anterior (...) se aprehende lo que una cosa real es en realidad: igual, o parecida, o completamente distinta de la anterior. (Zubiri, 1982, pp. 56, 60)
\end{abstract}

En esta modalidad de la semejanza se encuentra, por lo demás, la raíz de la ambigüedad y la polisemancia que caracterizan, lingüísticamente hablando, al funcionamiento simbólico.

De lo anterior podemos concluir que el qué acerca del cual se juzga en una función simbolizante se encuentra situado en el momento que cierra la estructura intelectiva campal de un juicio posicional, a saber, la realización de algo simplemente aprehendido en una cosa inteligida en aprehensión primordial. La función simbolizante implica, pues, que lo situado en el polo simbolizante sea una realidad aprehendida ya en intelección dual. Por lo tanto, la explicación noológica de la función simbolizante remite normalmente al modelo de carácter predicativo, aunque sabemos ya que, si esta función se dispara a partir de la percepción visual de los elementos situados en el sustrato material: el stimulus, la afirmación en la que consiste propiamente la función simbolizante debe tener como antecedente estructural necesario un juicio de carácter posicional.

El punto de partida para llegar a la anterior afirmación no es, como hemos visto, propiamente noológico, sino simbológico, pues en las propuestas de Zubiri no se encuentran datos para deducir estas afirmaciones. Desde esa segunda perspectiva es de donde debemos concluir que, normalmente, en la vida diaria, las personas son remitidas simbólicamente a determinadas realidades $y$, en este proceso, el polo remitente lo configuran cosas ubicadas en el plano de la cultura: cosas-sentido, diría Zubiri. Esto significa que se captan con todas sus notas y su significado en la vida cotidiana. De otro modo, no podrían operar las leyes simbológicas que hemos mencionado. 
Para terminar, hemos estado diciendo que la función simbolizante implica, noológicamente hablando, una intelección dual en la que desempeña un papel propio la semejanza, simbológicamente formulada como una relación funcional de motivación entre los polos de lo simbolizante y de lo simbolizado. Esto es relevante porque el proverbial debate entre quienes defienden que los símbolos, por consistir en una remitencia de carácter motivado, excluyen cualquier tipo de convención entre sus usuarios y quienes defienden con radicalismo que no existe tal motivación, puesto que toda relación es fruto de enfoques mentales desde los cuales se da el acercamiento a la realidad, parece poco consistente.

A partir de los planteamientos de Zubiri, queda claro, entonces, que la relación de semejanza que se puede establecer entre los polos implicados, sobre la base de determinados rasgos propios de éstos, se da siempre en el plano de la cultura. En este sentido, podría afirmarse, con razón, que el campo de la cultura es un gran mecanismo de convenciones sociales y, simultáneamente, una matriz cultural sólo se construye en la interacción cotidiana de los seres humanos con las cosas que utilizan y significan algo para ellos. Al respecto, U. Eco (1978) ya había adelantado que no rinde mucho fruto incorporar en la semiología una contraposición entre motivación y convencionalidad, sino más bien, conviene articular la relación de motivación con el enfoque de la culturalidad.

\section{Conclusión intermedia}

Como vimos en la introducción, de lo que trata este estudio es de esclarecer la naturaleza de la función significante, la función simbolizante y los dinamismos evocantes o simbólicos. Adelantando un tema que abordaremos en la segunda parte, a saber, el hecho de que estos dinamismos simbólicos se disparan, tanto a partir del manejo ritual de objetos simbólicos como a través de una narrativa que ostenta el mismo carácter, nos pareció ilustrativo comenzar con el esclarecimiento de los conceptos de función significante y función simbolizante, así como las semejanzas y diferencias que existen entre ellos. Esto es lo que hemos tratado de conducir a buen puerto en esta primera parte.

Al respecto, lo que hemos observado es que, si bien, ambas funciones tienen en común un hecho de conectividad, en realidad se configuran, sobre todo, por lo que las diferencia. $Y$ han sido los acercamientos lingüísticos, simbológico y noológico los que han contribuido a delinear los contornos de las citadas semejanzas y diferencias. 
De este modo, comprobamos que la corporalidad que opera en relación con la función significante y la función simbolizante, así como la razón que rige la conectividad en ambos casos, muestra una convergencia en relación con el enfoque noológico desde el que se inteligen ambas funciones, esto en cuanto a la explicación de los modos como se relaciona aquello que se quiere inteligir y la cosa desde la cual se lleva a cabo dicha intelección, también en cuanto al modo como se lleva a cabo la afirmación propiamente dicha.

Específicamente, las características auditivas de los sonidos que se relacionan conectivamente con las representaciones de determinadas cosas en la función significantepalabra son determinantes para que pueda darse un reconocimiento de los mismos, esto en orden al establecimiento de dicha conexión, la cual se posibilita finalmente por el carácter convencional y no motivado de dicha vinculación. Ahora bien, advertimos que se da una convergencia entre lo que implica este acercamiento lingüístico y el modo de intelección que se explica a través de la igualdad -detrás del cual se descubre un tipo de habitudes sociales-; esta forma de intelección, a su vez, guarda cierta correlación con el modo posicional de la afirmación.

Así, el conjunto de estas observaciones nos permite concluir que si bien la función significante se describe apropiadamente, en el momento de la emisión, como una expresión de la fase de afirmación de la intelección dual -expresión de realización, explicitó Zubiri- en el momento de la recepción, por su parte, debe ser descrita como la realización de una expresión.

Por otro lado, los rasgos, en muchos casos visuales, de las cosas puestas en una relación conectiva de carácter simbolizante en la función homónima son determinantes para que pueda establecerse el vínculo motivado correspondiente. Este hecho converge con el modo de intelección que funciona a través de la semejanza; el cual, a su vez, guarda una cierta correlación con la afirmación en modo predicativo.

De esta forma, la función simbolizante puede explicarse, noológicamente, como una forma de juicio predicativo en el que la "idea" de una cosa se realiza en otra, la cual se intelige como semejante -como una de las posibilidades-en relación con la primera. 


\section{Los dinamismos simbolizantes}

Aclarada ya la naturaleza de las funciones significante $y$ simbolizante, llegamos finalmente a la explicación del funcionamiento de los dinamismos evocantes o simbolizantes. Llevaremos a cabo esta tarea en dos pasos: en el primero esclareceremos la naturaleza simbológica de los mismos; en el segundo, haremos lo propio desde un enfoque noológico.

\subsection{Estatuto simbológico}

Hemos adelantado ya, en los párrafos donde analizamos simbológicamente la naturaleza de la función simbolizante, algunos de los rasgos que identifican también a los dinamismos simbólicos. Llevamos a cabo ese ejercicio desde la perspectiva del stimulus, el referente, la corporalidad, el carácter del vínculo que se da entre los polos de lo evocante y lo evocado, y el contexto intrasistémico a través del cual funcionan. A continuación, presentaremos otros rasgos, así como nuevos matices de los anteriores, lo cual permitirá describir la naturaleza de dichos dinamismos.

En cuanto a la corporalidad que interviene en relación con el polo de lo evocante, hay que decir que, al igual que la función simbolizante, quedan implicados los órganos y procesos fisiológicos de la visión. Sin embargo, en el caso específico que nos ocupa, es indispensable adoptar una perspectiva más amplia que desborda lo meramente fisiológico. De este modo, no se trata solamente de la visión de eventos observables, sino de una mirada que se dirige, finalmente, al conocimiento comprometido- de las personas en cuanto tales, y a los misterios últimos de la vida y la acción de los seres humanos en la historia. Por ello, habría que nombrarla, no tanto una visión, sino una contemplación.

En cuanto al carácter del vínculo que se establece entre el polo de lo evocante y lo evocado -fundamento del fenómeno de la significaciónhay que decir que los dinamismos simbólicos, simbológicamente analizados, funcionan en torno al eje de la remitencia motivada y configuran, por tanto, un fenómeno de evocación, por medio del cual, lo evocado se hace presente. Como en el caso de dicha remitencia, la evocación se establece sobre la base de uno o varios rasgos de semejanza, contraste o contigüidad física que comparten las cosas-sentido ubicadas en el polo de lo evocante con las entidades del polo de lo evocado. Dicho de otro modo, interviene un tertium comparationis que funciona como gozne entre estos contenidos. Sólo que, en el caso que nos ocupa, el modo de operar de la evocación es trastocado radicalmente por obra de 
las realidades implicadas en el polo de lo evocado. Volveremos luego sobre este tema.

También es importante destacar la función que desempeña el material narrativo de impronta simbólica en la puesta en marcha de los dinamismos simbólicos, de manera particular, cuando éstos constituyen una expresión de experiencias de carácter religioso o mítico, conceptos más o menos emparentados, según la tendencia teórica desde la que se emprenda el análisis. Prácticamente se da un consenso entre antropólogos, historiadores de la religión y psicólogos de la experiencia religiosa por lo que toca al hecho de que, en las religiones sustentadas, en términos generales, por todos los pueblos a lo largo de la historia, marchan inseparables una vertiente mítica y una vertiente simbólico-ritual. De acuerdo a la propuesta clásica de Brandon (1975), el plano del mito cumple la función de explicitar narrativamente los contenidos transmitidos por los símbolos y los rituales; éstos a su vez se representan de manera dramatizada 0 teatral en el plano del drómenon; la ejecución ritual y simbólica constituye una representación, incluso mimética e icónica, de los eventos primigenios que una comunidad considera determinantes para su existencia como tal. En la narrativa mítica, por su parte, se plasma la memoria que explicita oralmente los eventos teatralizados.

Prosigamos nuestra disquisición. Los dinamismos simbólicos, a diferencia de las demás funciones remitentes, contribuyen a establecer un flujo de comunicación entre personas, sobre todo a través de referencias de sí mismas, es decir, acerca de aquellos rasgos que las constituyen como tal persona. Ahora bien, lo que identifica a estos niveles de la comunicación es que ésta se produce en el contexto de unos vínculos de carácter afectivo, de entrega mutua y compromiso, los cuales quedan afectados de modo significativo por dicho evento comunicativo. De este modo, los dinamismos simbólicos cumplen una función de significación, de comunicación y de vinculación entre personas individuales y entre los miembros de un grupo.

Entonces, para entender el modo de funcionamiento de los dinamismos simbólicos hay que tener en cuenta el contexto que proporciona lo que nombraremos la función focalizante; diferente del sistema intrasimbólico. Ésta es ejercida por racimos simbólicos de toda índole, así como por conjuntos de prácticas rituales. Sin embargo, si bien el papel que cumple esta función es a todas luces importante, lo es en diferente medida; en todo caso, puede llegar a constituir, incluso, una condición necesaria 
para que comience a operar dicho dinamismo. De este modo, muchas cosas que encierran un fuerte potencial simbólico en relación con un grupo específico, cuando son percibidas de manera aislada, pueden resultar intrascendentes como tales, sin embargo, ubicadas en un contexto focalizante adecuado, ponen en marcha dicho potencial.

Así, se comprende mejor por qué -si bien el modelo de evocación que define a los dinamismos simbólicos tiene que ver, primordialmente, con el funcionamiento de la motivaciónde todos modos, el papel que desempeña la función focalizante es, en muchos casos, prácticamente indispensable. Ello sugiere que, también en relación con el funcionamiento de los dinamismos simbólicos, interviene una cierta dosis de convención, si bien ésta no es lo determinante, en contraste con la función significante. En ésta última - lo hemos visto-, los rasgos de las cosas contenidas en el polo de lo remitente solamente disparan la mecánica de la convención, dicho en un sentido lato: crean el lazo. En los dinamismos simbólicos, por el contrario, la convención que implica la función focalizante en ningún sentido crea el vínculo sino que, simplemente, focaliza la atención hacia los rasgos sobre los que está montada dicha motivación.

Antes de terminar, hay que perfilar otra propiedad que distingue a los dinamismos simbólicos con mayor nitidez que en el caso de la función simbolizante; se trata de la inserción de los mismos en el plexo de las dinámicas y las contraposiciones de toda especie, incluso violentas, que caracterizan a la vida social en la actual fase por la que cursa el sistema social vigente; en estrecha conexión con lo anterior, se encuentra su capacidad de afectar y ser afectados por las mismas. Este tema ha sido desahogado competentemente por algunos representantes de diferentes enfoques científicos, entre ellos Barthes (1990, pp. 75-79, 239-243). Últimamente, Marcos Ornelas (2013), apoyado en los planteamientos de N. Luhmann acerca de los sistemas sociales, ha sacado a la luz el rol que han venido desempeñando los símbolos religiosos específicamente, los sacramentos de la liturgia católica- en el contexto de los grandes cambios sociales y civilizatorios que se han dado en el así llamado Occidente, a lo largo de su época cristiana y viceversa.

\section{Estatuto noológico}

El procedimiento que seguiremos en esta segunda sección consistirá en proyectar el funcionamiento de los dinamismos simbólicos sobre el plexo de la noología zubiriana, tal como es presentada en el tercer volumen de 
la trilogía. Con ello, pensamos que se posibilitará encontrar una respuesta más nítida a la pregunta acerca de la naturaleza de dichos dinamismos y, por lo mismo, acerca de la diferencia que existe entre éstos y la función simbolizante.

Dividiremos la exposición en dos pasos. En el primero, veremos cómo la misma forma en que la simbología presenta, por definición, lo que son los dinamismos simbólicos conduce, con el deseo de profundizar estas mismas concepciones, al análisis del funcionamiento de la intelección en profundidad. También veremos cómo la manera, según presenta Zubiri la marcha de la razón, justifica esta incursión en el análisis de la misma, a fin de lograr una mejor comprensión de dichos dinamismos. En el segundo paso, por su parte, completaremos esta clarificación desde una revisión del tercer momento del método del conocimiento en el modo de compenetración.

\subsection{Dinamismos simbólicos y marcha de la razón}

\subsubsection{La intelección como marcha}

Para entender mejor el modo de funcionamiento de los dinamismos simbólicos, hay que entender que la razón es presentada por Zubiri, ante todo, como una marcha, la cual parte desde una cosa real y se dirige, a impulso de la realidad misma, hacia la pura y simple realidad, hacia el mundo -unidad de respectividad de lo real-: "marcha es búsqueda de realidad", afirma nuestro filósofo. Este inteligir en búsqueda es una actividad que, formalmente, se llama pensar. De este modo, inteligimos que una cosa es algo real respecto, no de otras cosas, sino de la pura y simple realidad; comprendemos así lo que es en profundidad. La realidad es, por lo mismo, inteligida por sí misma. Esto implica que inteligimos algo allende el campo (Zubiri, 1983, pp. 17-26).

Ahora bien, la concepción de lo que son los dinamismos evocantes, presentada más arriba desde una perspectiva simbológica, dio por sentado que en el polo de lo evocado se sitúan seres que las personas consideran de naturaleza sobrehumana o divina, o bien aspectos de aquello que las constituye a ellas mismas como tales, los cuales posibilitan un conocimiento recíproco más profundo que el que suelen proporcionar los acercamientos interpersonales de carácter meramente instrumental.

Ante esto, lo que queda claro es que la simbología no acierta a redondear estas nociones, sobre todo por carecer del instrumental analítico necesario. Esta es la razón por la cual los tratados correspondientes no toman en cuenta o no los analizan de manera específica, por ejemplo, a los símbolos que remiten a realidades 
divinas, sino les conceden una mención que los sitúa a la par del resto del universo simbológico. El breve -y clásico - tratado de Guiraud (1979) ofrece un ejemplo muy claro al respecto. Este es el principal motivo por el que la simbología se encuentra incapacitada para distinguir plenamente, por sí misma, entre los dinamismos simbólicos y la manera cómo opera la función simbolizante.

En contraste con lo anterior, la filosofía acerca de Dios, de estirpe zubiriana, aclara que, a través de las concepciones que los seres humanos comparten acerca de la divinidad, son conducidos finalmente, a partir del hecho de la religación, a una realidad absolutamente absoluta, la cual sobre el sustrato de una aproximación de carácter noológico, hay que inteligir como el fundamento de ese poder de lo real con el que ellos mismos se ven confrontados en dicha experiencia de religación. Por otro lado, el acercamiento antropológico, igualmente proporcionado por nuestro autor, ayuda a comprender que, allende la realidad humana, las personas tienen una forma y un modo de realidad propios, a saber, una personeidad, una personalidad y una realidad relativamente absoluta, así como un ser propio, que se delinea como Yo.
Ahora bien, el punto crucial es que la comprensión de estos aspectos de la naturaleza humana y de la realidad divina han llegado a ser accesibles, de manera más nítida y completa, solamente a través de la marcha de la razón. Veamos esto con más calma.

\subsubsection{El principio de la intelección en profundidad}

La ya citada búsqueda de la realidad en profundidad no ocurre en el vacío y de manera caótica, sostiene Zubiri, por el contrario, encuentra una referencia insustituible a través de una mensura de realidad, a saber, la formalidad constitutiva misma "de suyo", desplegada en lo campal. Ulteriormente, en el esfuerzo por dilucidar lo que es la realidad como mensura, nuestro autor explica lo que significa ese principio: éste no consiste en otra cosa, sino en ser fundamento de lo campal. Zubiri se explaya que por el hecho de que la realidad es abierta, por ello funda. Pero no sólo funda, sino fundamenta. Esto significa que lo fundante otorga, desde sí mismo, el carácter de realidad -que le pertenecea lo fundado. De este modo, la realidad fundada se realiza "por y en la realidad de fundante" (Zubiri, 1983, p. 46). "Ser principio es estar realizándose como principio”, remata Zubiri. Simultáneamente, la realidad es principio de intelección porque en la realidad previamente actualizada, se actualiza de nuevo la cosa real. 
A través de la marcha de la razón, la realidad no es ya inteligida como nuda formalidad de realidad -como sucede en la aprehensión primordial-, ni tampoco como realidad-objeto lo real puesto en forma de objeto-, sino como realidad-fundamento de lo campal (Zubiri, 1983, p. 47). Gracias a esto comprendemos, hasta este momento -en una primera formulación argumentativa que consideramos parcial y que será completada más adelante- que, en el caso de los dinamismos simbólicos, la puesta en marcha de la evocación apunta hacia lo que nológicamente hemos descubierto como realidadfundamento.

\subsubsection{Justificación del tema desde la marcha de la razón}

Repasemos ahora otros aspectos de la marcha de la razón que confirmarán los anteriores aciertos y, por lo mismo, permitirán delinear más exquisitamente una explicación noológica de la naturaleza de los dinamismos simbólicos, así como el motivo por el que se distinguen de la función simbolizante. Lo haremos, no a partir de la explicación simbológica de lo que representan los dinamismos simbólicos, sino desde las mismas aportaciones zubirianas acerca de la marcha de la razón. De este modo, quedará suficientemente justificado el esfuerzo emprendido en esta parte del trabajo.
Las aportaciones que nos interesan destacar son las que se refieren a la mensura y al canon, es decir a los dos momentos de la intelección racional - la creación y la atribución-, finalmente, a la noción de mentalidad.

Anteriormente, hemos introducido el tema de la mensura. En este momento lo que resulta importante tener en cuenta, según lo que sostiene Zubiri, es que el canon puede ser entendido como la misma realidad en su calidad de conceptuada, pero no siempre tiene que ser así: "puede ser, en efecto, una mensura, por ejemplo, emocional, una mensura metafórica, etc.", añade el autor (Zubiri, 1983, p. 59).

De este modo, cuando se asevera, por ejemplo, que la relación interpersonal en profundidad puede circular por los cauces de los dinamismos simbólicos, lo que se quiere dar a entender es que no se trata solamente de que en estas oportunidades se pongan en funcionamiento determinadas figuras de lenguaje o salgan a relucir objetos cargados de simbolicidad, sino que el modo mismo de acceso a las formas y a los modos de realidad implica una estructura noológica de carácter simbólico.

Otra cosa que nos interesa destacar, en aras del tema que nos ocupa, es lo que acontece en lo que Zubiri nombra el primer momento 
de la intelección racional, a saber, el de la creación. Cuando se pone en marcha el tercer modo de dotar a la realidad profunda de contenido, es decir la libre construcción, la creación de dicho contenido incluye necesariamente -viendo las cosas desde la intelección- la unidad de las notas que lo componen: "Lo racional de esta creación consiste en ser creación en y de unidad fundamental' (... de este modo) lo racional de la creación está, pues, en la estructuralidad" (Zubiri, 1983, p. 113). Pues bien, esta unidad, al ser realizada, se convierte en una estructura real profunda. De hecho, concluye Zubiri, lo propio de lo real, en cuanto real, es ser un sistema constructo.

Ahora bien,en el análisis de los dos momentos de la intelección racional, el autor se cuida de dilucidar que la unidad de las notas que componen el contenido no precisa tener, como única referencia, lo conceptual: "Se puede inteligir que aquel contenido tiene la 'unidad' -sólo poéticamente aprehendida- de lo metafórico" (Zubiri, 1983, p. 112).

Finalmente, Zubiri desarrolla otro concepto que viene muy al caso en relación con el tema que estamos desarrollando. Es el concepto de forma mentis, al cual asigna el nombre de mentalidad. A través de mismo, nuestro autor pretende explicar y fundamentar el papel determinante que lo real desempeña en la intelección en profundidad.

Aquí, lo decisivo para nuestro tema es que el papel decisivo de lo real en la intelección en profundidad puede determinar que una forma de esta habitud de lanzamiento -en que consiste la forma misma de la mens-, sea por ejemplo,"poética" y no necesariamente "teorético-científica" (Zubiri, 1983, pp. 147-155).

\subsection{Los dinamismos simbólicos en el contexto de "el" método}

Este camino que hemos emprendido hacia una comprensión más acabada de la naturaleza de los dinamismos simbólicos quedaría incompleto si dejáramos de lado el tema de "el" método -esto es, su identidad noológica-.

Siguiendo los pasos de Zubiri, repitamos que el método, como modo intelectivo,"constituye el 'cómo' de la búsqueda del fundamento en el mundo" (Zubiri, 1983, p. 203). Puesto que, como modo intelectivo, es un "abrirse paso en el mundo", entonces método es lo mismo que vía, y lo es porque a través de ella transitamos, desde la cosa real en el campo, hacia su fundamento mundanal. Método es, en todo caso, una vía que atraviesa entre diferentes formas de realidad (Zubiri, 1983, p. 204) y, como tal, se desenvuelve en tres momentos: el sistema de referencia, el esbozo 
de posibilidades y la experiencia o probación física de realidad.

\subsubsection{Dinamismo simbólico y experiencia}

El tercer paso del método, la experiencia, implica que lo irreal podría insertarse y actualizarse en lo real, pero no como mera realización, sino probando si se inserta (Zubiri, 1983, p. 226). Es la probación física de realidad. Por el hecho de que esto implica una verdadera probación de si lo irreal se inserta en lo real, la explicación de la misma resulta muy ilustrativa acerca de la forma como funcionan los dinamismos simbólicos, sobre todo, cuando nos referimos al momento recipiente. Por ello sostenemos, en primer lugar, que estas vivencias de comunicación y conocimiento entre las personas, o por parte de éstas con respecto a la realidad divina, son un modo de probación física de realidad, a saber, de realización de lo que ellas o Dios mismo "podrían ser"; la inserción de un esbozo en la realidad profunda. Ello queda más de manifiesto cuando acudimos a la explicación zubiriana acerca de uno de los modos de esta probación de la viabilidad.

De los cuatro modos de experiencia formulados por Zubiri el experimento, la compenetración, la conformación y la comprobaciónel segundo apunta directamente a la relación profunda entre seres humanos, así como a la relación con Dios, fundamento del ser de la persona. Y es que la compenetración consiste en el "intento de asistir (...) a la visión de lo real lograda desde su propia interioridad (...) fundada en una instalación del experienciador en lo experiencial" (Zubiri, 1983, p. 249). Es una "perichóresis, no de realidad, pero sí de modos de actuar y de conducirse" (Zubiri, 1983, p. 249).

De este modo, notamos ya un primer acercamiento semántico - por decir lo menos- entre la experienciacompenetración y los dinamismos simbólicos, lo cual confima lo que habíamos observado ya en los primeros párrafos acerca de la marcha de la razón. El motivo por el que nos animamos a expresar esta observación preliminar es que, como hemos visto ya, en su escueta descripción antropológica del símbolo, Zubiri (2007) sostiene que esta expresión "quiere decir co-volición" (p. 286), lo cual resulta significativo para nuestro tema.

Ahora bien, este penetrar-con no acontece de modo directo - por una suerte de comunicación telepática-, sino a través de cosas. Tratándose de los seres humanos, "cosa" es el cuerpo, a través del cual se expresan de manera paradigmática -aquí hay que tener en cuenta la noción de "función somática", por la que el otro es "algo corpóreamente presente a mí” (Zubiri, 1998, p. 62). Al respecto, Antúnez (2006, pp. 306, 479) presenta otra expresión de estirpe 
zubiriana: la noción de cuerpo-soma como "persona expresa". También son "cosas" las palabras en el estrato del stimulus y, en conjunto, el lenguaje, como hemos constatado. De ahí en adelante, todo podría ser utilizado como medio de comunicación, en un contexto de viabilidad cultural y, por ende, como medio a través del cual se implementa la experienciacompenetración.

En el caso de la relación con Dios, Zubiri había enfatizado que, a lo que obtenemos acceso, a través de la vía, es a la presencia constitutiva de Dios a través de las cosas, donaciones suyas, en cuanto presencia ensimismante, asunto muy recalcado por Zubiri:

Jamás, ni en el acceso supremo de los grandes místicos, se accede a Dios sin las cosas o fuera de ellas: se accede siempre a Dios en las cosas. Las cosas reales son la presencia personal de Dios. (Zubiri, 1998, p. 186)

Por ello, éstas son, a su vez, "sede" y "vehículo" de Dios y, en este sentido, "deidad". Sólo de este modo pueden ser realidad y sólo así poseen ese poder que se le impone al ser humano. De esta manera, Dios como fundamento constituyente del poder de lo real, es experienciado como trascendente, pero en las cosas. Asimismo, cada cosa posee un fondo trascendente, de suerte que, al llevarnos a sumergirnos en ella misma, resulta que estamos en Dios en ella (Sáez, 1996, pp. 222-223).
En coherencia con lo anterior, Zubiri cita explícitamente como un modelo de esta forma de experiencia a la alianza entre Dios y el pueblo de Israel, experiencia adquirida por éste a través de su historia: "la compenetración adopta aquí la forma de una gran experiencia histórica" (Zubiri, 1983, p. 251).

\subsubsection{Compenetración y dinamismos simbólicos}

En relación con los diferentes modelos que puede adoptar la experiencia, Zubiri, en su filosofía acerca de Dios, desarrolla una vía estrictamente demostrativoconceptual -que guarda un parentesco con la experienciacomprobación- (Sáez, 1996, p. 221), para argumentar acerca de la realidad de Dios. De igual modo, se puede aplicar esta vía para demostrar el hecho de la intervención salvífica de Dios a través de la historia. Pero éste no es el único camino posible, ni resulta suficiente para construir una relación plena. Lo que nos interesa recalcar es que, a la par del mismo, existe un acceso a la realidad y a la acción de Dios, fundamento de mi Yo, a través de la fe, entendida como entrega - la voluntad de fundamentalidad-, la cual incluye necesariamente una vertiente intelectiva, mas no necesariamente demostrativa. De este modo, Zubiri llega a declarar que: 
El hombre puede alojar por así decirlo más o menos espontáneamente, en el ámbito de lo real a que nos estamos refiriendo, la realidad absolutamente absoluta de Dios. Si para este hombre no hubiera "demostración", esta admisión de la realidad de Dios no estaría intelectivamente justificada; pero esta admisión sería una auténtica fe (...). (Zubiri, 1998, p. 271)

Ahora bien, una de las formas posibles en las que se desarrolla este camino que Zubiri califica como "espontáneo", es el de las vivencias en las que se disparan los dinamismos simbólicos -por lo anteriormente dicho, esto no implica una incompatibilidad entre la vía demostrativa y la experiencia simbólica-. De este modo, el dinamismo que desemboca en una certeza no es tributario de la lógica del razonamiento, sino de la fuerza de la semejanza, el contraste y la contigüidad física -finalmente, del impulso de la realidad misma, añadiría nuestro autor-.

Así, en el transcurso de su relación con Yahvé, el pueblo de Israel experimenta a través de los eventos trascendentales $y$, sobre todo, benéficos de su historia. Ésta opera como el polo que evoca y hace presente el talante bienhechor de quien los liberó de la esclavitud egipcia (chesed v'emet divinas). Esto es lo que posibilita que esta historia constituya un punto de partida y un fundamento de otras formas de evocación de "la" presencia (las tablas de la ley, la tienda-tabernáculo, entre otras).

Ahora bien, la relación que puede existir entre la experienciacompenetración y los dinamismos simbólicos se pone de manifiesto, no sólo en las relaciones entre los seres humanos y la divinidad, sino a través de los vínculos que éstos suelen tejer entre sí mismos. Como hemos estado observando, en las cosas, a través de los dinamismos simbólicos, anida la capacidad de evocar y, por lo mismo, exteriorizar fibras muy íntimas de la experiencia humana. Ahora bien, en conexión con esto, no hay que perder de vista que el funcionamiento de la dinamicidad simbolizante implica un evento de "co-volición", que ya hemos mencionado anteriormente. Esta es la conocida frase de Zubiri:

Pero hay todavía una función signitiva más compleja: aquel modo de signar las cosas, las cosas señaladas, no por lo que tienen de cosa, sino por consignación de las personas que van a converger en aquella cosa. Entonces el signo adquiere un carácter de símbolo. Símbolo quiere decir co-volición». (Zubiri, 2007, pp. 285-286) 
De este modo, los dinamismos simbólicos proporcionan una plataforma de encuentro entre las personas, en cuanto tales. De igual manera, a través de los mismos, se pone en marcha una función de comunicación al servicio de la comunión, esto es, la "versión" en comunidad (Zubiri, 1998, p. 67), y en forma de "compenetración atractiva", e implica una aceptación de la "compañía" de los demás -término con el que Zubiri designa el "poder" de las personas- (Zubiri, 2007, pp. 269-270, 274, 321-322). Esto sucede en contraste con la función simbolizante, la cual evoca realidades diversas -igualmente, a través de referencias motivadas-, en una labor de significación-conocimiento de la persona de otro, "en cuanto otro", labor que opera perfectamente en un ámbito societal (Zubiri, 1991, pp. 213-214; Zubiri, 1998, pp. 66-67).

Finalmente, si bien la exposición que hemos presentado acerca de la marcha de la razón no esclarece directamente la naturaleza del vínculo que se establece entre el polo de lo evocante y el de lo evocado, sin embargo, sí lo hace de manera indirecta. Esto quiere decir que, sin perder el carácter motivado del mismo, no obstante, se vuelve una entidad claramente acotada en sus alcances -en contraposición con lo que sucede en la función simbolizante-. De este modo, toda dinamicidad simbolizante posee, ciertamente, la virtud de evocar y hacer presentes las realidades trascendentes a las que apunta la marcha de la razón - la realidadfundamento de la cosa campal-, sin embargo, mantiene intacta la inaccesibilidad constitutiva de las mismas. Asimismo, todo dinamismo simbólico se encuentra circunscrito por una dosis de apofaticidad irrenunciable.

\section{Conclusión}

Hemos iniciado este estudio acerca de la naturaleza de las acciones y las cosas simbólicas advirtiendo que procuraríamos aplicar, a lo largo de la misma, un procedimiento de carácter interdisciplinar; por ello, hemos iniciado tomando prestados algunos conceptos del campo de la lingüística, la simbología y la filosofía hermenéutica, y los hemos puesto a dialogar con la noología de Xavier Zubiri y con algunos planteamientos de la filosofía de Dios y de la antropología, también de Zubiri. A estas alturas, lo que debemos concluir es que, efectivamente, hemos podido establecer mejor la naturaleza del lenguaje, entendido como una activación de la función significante; la naturaleza de los símbolos, entendidos como una función simbolizante; finalmente, la naturaleza de los dinamismos evocantes o simbólicos; todo lo cual ha contribuido, también, a enfocar mejor las semejanzas y la distinción entre estas expresiones. Hemos observado además que las categorías 
que contribuyen de manera particular a lograr este cometido son las de modo de remitencia y polo de lo remitido. Comencemos con la primera.

Enfocado lingüísticamente, el modelo de remitencia que describe y distingue a la función significante apunta al hecho de la convencionalidad. En contraste con esto, desde una perspectiva simbológica, la remitencia que opera en el caso de la función simbolizante y de los dinamismos evocantes ostenta un carácter motivado. De este modo, aparece con nitidez la naturaleza propia y la distinción que existe entre la función significante y la función simbolizante -teniendo en cuenta que no es posible, en este momento, establecer una diferenciación entre la función simbolizante y los dinamismos evocantes-. El análisis de la aprehensión primordial, por su parte, contribuye a profundizar esta comprensión de las funciones. En particular, hay que tener presentes los modos de presentación de la realidad, relacionados, a su vez, con la corporalidad y la naturaleza del stimulus, implicadas en estas operaciones.

Hemos observado también que, desde una hipótesis noológica parazubiriana, resulta posible avanzar en la comprensión de la función significante - perfilada ahora como una realización de expresión-, y de la función simbolizante - como una afirmación-; con ello se comprende mejor la distinción entre ambas. Por lo que toca a la primera, resalta la función que cumple la hexis, lo cual enfatiza la no ergía, en cuanto realidad, y el carácter social del lenguaje. Con la introducción del concepto de remitencia, la explicación simbológica de la función simbolizante ayuda a completar la comprensión de la naturaleza de la misma, en cuanto explicada noológicamente $y$, de este modo, distinguirla de otras operaciones del logos.

Por lo que toca al polo de 10 evocado, el aborde noológico, articulado con algunas aportaciones de la filosofía de Dios y de la antropología zubiriana, contribuye a la comprensión y la diferenciación entre la función simbolizante y los dinamismos evocantes. Desde este punto de observación llegamos a vislumbrar que las relaciones de fe que establecen los hombres y mujeres con Dios, así como la comunión y la aceptación mutua que cultivan entre sí mismos(as), se expresan y perciben, entre otras posibilidades, a través de los dinamismos simbólicos. En este capítulo cumple un papel relevante la explicación de la marcha de la razón en pos de la realidad-fundamento, las nociones de mensura, creación y mentalidad, así como el método como compenetración. 


\section{Referencias bibliográficas}

- Antúnez, J. (2006). La intersubjetividad en Xavier Zubiri. Roma: Editrice Università Gregoriana.

- Audi R. (Coord.) (1999). "Laws of Thought". The Cambridge Dictionary of Philosophy (p. 489). Cambridge: Cambridge University Press.

- Barba, F. y Cabrera, J. A. (2003). Diagnóstico de comunicación interna, para la Universidad de las Américas-Puebla (pp. 7-8). (Tesis de licenciatura). Universidad de las Américas. Puebla, México. Recuperado de: http://catarina.udlap.mx/u_dl_a/tales/documentos/lad/barba_g_f/ capitulo2.pdf

- Barthes, R. (1990). La aventura semiológica. Barcelona y Buenos Aires: Editorial Paidós Ibérica.

- Berlo, D. K. (2008). Procesos de comunicación: Introducción a la teoría y a la práctica (pp. 27-35). Buenos Aires: El Ateneo.

- Brandon, S. G. F. (1975). Diccionario de religiones comparadas, II (p. 1,241). Madrid: Cristiandad.

- Corcoran, J. (1999). Laws of Thougth. En The Cambridge Dictionary of Philosophy (p. 489). Cambridge: Cambridge University Press.

- Eco, U. (1978). Tratado de semiótica general (pp. 322-324). Barcelona y México: Lumen, Nueva Imagen.

- González, A. (1994). Un solo mundo. La relevancia de Zubiri para la teoría social. (Tesis doctoral) Universidad Pontificia de Comillas. Madrid, España. Recuperado de: http://www.uca.edu.sv/filosofia/ admin/files/1201404090.pdf

- Guiraud, P. (1979). La semiología. México: Siglo XXI.

- Hjelmslev, L. (1971). Prolegómenos a una teoría del lenguaje. Madrid: Gredos.

- Klinkenberg, J. M. (2006). Manual de semiótica general (pp. 96 ss.). Bogotá: Fundación Universidad de Bogotá Jorge Tadeo Lozano.

- Ornelas, M. (2013). La diferenciación moderna de la religión: la misa latina (1517-1570). México: El Colegio de Sonora, Universidad Iberoamericana.

- Pintor Ramos, A. (1987). El lenguaje en Zubiri. Cuadernos Salmantinos de Filosofía (14). (pp. 93-133). 
- Ricoeur, P. (1995). Teoría de la interpretación. Discurso y excedente de sentido. México: Siglo XXI. . (1990). Freud: una interpretación de la cultura. México: Fondo de Cultura Económica.

- Sáez, J. (1996). La accesibilidad de Dios: su mundanidad y trascendencia en X. Zubiri. Salamanca, España: Universidad Pontificia de Salamanca.

- Saussure, F. (1982). Curso de lingüística general. México: Nuevomar.

- Shannon, E. (1948). A Mathematical Theory of Communication. The Bell System Technical Journal, 27, (pp. 379-423 y 623-656). Recuperado de http://www.essrl.wustl.edu/ jao/itrg/shannon.pdf

- Zubiri, X. (2007). Sobre el hombre (pp. 288-296). Madrid: Alianza Editorial y Fundación Xavier Zubiri.

_.(1998). El hombre y Dios. Madrid: Alianza Editorial y Fundación Xavier Zubiri.

. (1991). Inteligencia sentiente: Inteligencia y realidad (p. 50). Madrid: Alianza Editorial y Fundación Xavier Zuribi.

- (1983). Inteligencia y razón. Madrid: Alianza Editorial, Sociedad de Estudios y Publicaciones.

- (1982). Inteligencia y logos. Madrid: Alianza Editorial, Sociedad de Estudios y Publicaciones. 